\title{
A-scan echoencephalography in measurement of the cerebral ventricles
}

\author{
ANAND G. GARG AND ALEX. R. TAYLOR \\ From the Department of Neurological Surgery, Royal Victoria Hospital, Belfast, Northern Ireland
}

The first attempts at ultrasonic visualization of the cerebral ventricles were made by Dussik (1948), Ballantine, Ludwig, Bolt, and Hueter (1950), and Hueter and Bolt (1951), using the transmission method.

The possible use of the pulse-echo method (echoencephalography) for the diagnosis of hydrocephalus was suggested by Leksell (1956). Later Kikuchi, Uchida, Tanaka, and Wagai (1957) and de Vlieger and Ridder (1959) recorded echoes from the walls of the lateral ventricles. According to Gordon (1959), and de Vlieger and Ridder (1959), the width of the third ventricle can also be measured. ter Braak, Crezée, Grandia, and de Vlieger (1961) used pneumoencephalography to study the origin of ventricular echoes. Lithander (1961a) investigating hydrocephalus in children, thought that the lateral ventricular size could be measured with relative certainty and also confirmed the value of the technique in outlining an enlarged third ventricle. Ambrose (1963, 1964) expressed the width of the lateral ventricles, obtained at echoencephalography, as a fraction of the distance from the midline echo to inner skull table. A ratio of onefifth to one-sixth was considered normal, of one-quarter a slight dilatation, of one-third moderate dilatation, and of half or more as gross dilatation. Russo and Arnold (1964), and Dreese and Netsky (1964) also reported on the diagnosis of hydrocephalus. Schiefer and Kazner (1966) assessed the thickness of the remaining cerebral layer in infantile hydrocephalus from the lateral ventricle echoes. Umbach and Kley (1965) reported on the diagnosis and the control of progress by serial echoencephalograms in 75 children with hydrocephalus. Jacobi and Stephan (1965) detected a dilated third ventricle in 305 patients. Lapayowker and Christen (1965), in 66 patients, obtained lateral ventricle echoes, 1.4 to $2.2 \mathrm{~cm}$ from the midline, corresponding to the posterior portion of the lateral ventricles. Kessler (1965) and Gordon (1966), on the other hand, do not think that these echoes are a reliable indicator of ventricle size.

\section{METHOD}

The ventricular measurements obtained at echoencephalography were compared with the $x$-ray measurements made at pneumoencephalography.

ANATOMICAL CONSIDERATIONS The third and lateral ventricles are supratentorial structures. The third ventricle lies between the two thalmi, communicating in front with the lateral ventricles through the interventricular foramina and behind with the aqueduct of the midbrain. The septum lucidum and the third ventricle lie in the central plane of the brain.

The lateral ventricle is a C-shaped cavity lying within the cerebral hemisphere. It consists of a central body and three horns-anterior, posterior, and temporal-running into the frontal, occipital, and temporal lobes respectively.

The ventricular system on the two sides is normally symmetrical about a central plane. The ventricles may be distorted or asymmetrical, because of hydrocephalus or any space-occupying lesion.

RADIOGRAPHIC CONSIDERATIONS At pneumoencephalography, with the patient lying supine, the bodies of the lateral ventricles are shown in the antero-posterior radiograph as two triangles lying one on either side of the midline. Each triangle has a supero-medial, superolateral, and inferior angle. Joined to the triangles is a fainter shadow of the anterior horns. Between the two inferior angles lies the superior part of the third ventricle extending downwards for nearly 1 to $1.5 \mathrm{~cm}$.

To obtain perfect antero-posterior projection, the patient lies supine with the skull base line at $90^{\circ}$ to the film and $90^{\circ}$ to the table. The centre pointer is $3.8 \mathrm{~cm}$ above the level of the nasion, directed at the centre of the grid.

ULTRASONIC CONSIDERATIONS The shape of the ventricular system varies at different levels, and the distance from the lateral walls of the lateral ventricles to the midsagittal plane of the skull varies correspondingly. This makes it difficult to standardize the measurement of ventricles for different degrees of dilatation by echoencephalography. Moreover, the normal limits of the ventricular system are uncertain. It is thus essential to know which part of the ventricular system lies in the path of the ultrasonic beam.

Because of the differences in specific acoustic impedance 
of the cerebral tissue and the cerebrospinal fluid (1.59 and $1.51 \times 10^{5} \mathrm{~g} / \mathrm{cm}^{2} / \mathrm{sec}$ respectively, according to Kazner, Kunze, and Schiefer, 1965), echoes are given from both. walls of the third ventricle and the septum lucidum (the midline echo) and the lateral walls of the lateral ventricles (the ventricular echo). The part of the record. between the midline echo and the ventricular echo is almost echo free. The width of the midline echo is the width of the third ventricle.

A Siemen's Echoencephalograph USM I was used, equipped with a polaroid camera. The best ventricular echoes were obtained from a crystal position 0.25 to $0.5 \mathrm{~cm}$ above the tip of the ear. The ultrasonic beam must be narrow and non-divergent. It is parallel in the Fresnel zone (near-field) after which it diverges. As the length of Fresnel zone and the angle-of-divergence are dependent on the frequency and diameter of the crystal (which are themselves interdependent), the selection of crystal size is critical. According to the manufacturers the beam in the Fresnel zone, in practice, is not absolutely parallel but is bundled just before its end. Consequently, there is a slight increase in power, which is desirable because of attenuation. If the diameter and frequency of the crystal are chosen, so that this bundling takes place in the region of the particular structure examined, more prominent echoes are received. A barium-titanate crystal of $15 \mathrm{~mm}$ diameter was employed, pulsing at a frequency of $2 \mathrm{Mc} / \mathrm{sec}$. It has a Fresnel zone of $7.5 \mathrm{~cm}$ and an angle-of-divergence of $3^{\circ} 30^{\prime}$. The crystal has a pulse repetition rate of 430 pulses/sec and each pulse lasts for $1 \mu \mathrm{sec}$. It is applied at symmetrical positions on either side of the head.

To find out the exact site of the ventricular system traversed by the ultrasonic beam, as seen in an anteroposterior radiograph, the following study was done on a cadaver. Air was injected into the ventricle through a right frontal burrhole. Another small burrhole was made in the skull, at the position used for ventricular measurement by echoencephalography. A 6-mm wide Steinmann pin was introduced perpendicularly, through this burrhole, along the presumed path of the ultrasonic beam. A radiograph taken after this demonstrated the pin passing through the inferior angles of the body of the lateral ventricles and the upper part of the third ventricle (Fig. 1).

Measurements at echoencephalography were made from the centre of the midline echo to the rising flank of the ventricular echo. Measurements were made on radiographs, of the inferior angle of the body of the ventricles on a level with the upper part of the third ventricle, from the midline to the lateral wall.

\section{MATERIAL}

Eighty-seven patients were examined by echoencephalography and pneumoencephalography in that order. Of these, nine were discarded-because of poor ventricular filling in four and unsatisfactory radiographs in five.

Of the remaining 78 , nine were below 10 years, six between 10 and 15 years, and 63 were adults. Of the total patients, 10 were admitted with Parkinson's disease, 20

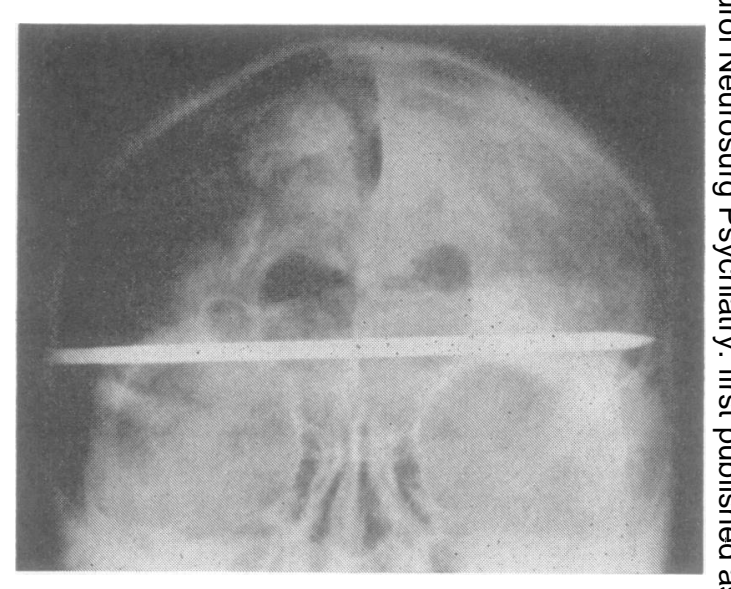

FIG. 1. Steinmann pin through a burrhole along the path of ultrasonic beam.

investigated for posterior fossa lesions, three for hydro- $\vec{\omega}$ cephalus, and the remaining 45 for supratentorial lesions.

\section{RESULTS}

With the help of a neuroradiologist the ventrit cular appearance, in terms of its apparent size, $\frac{\mathrm{A}}{\mathrm{c}}$ was classified into five grades: normal (up to $7 \mathrm{~mm}$, 0 minimal dilatation $(8-10 \mathrm{~mm})$, slight dilatation $]$ (11-13 mm), moderate dilatation (14-17 mm ,, and gross dilatation (above $18 \mathrm{~mm}$ ). The figures parentheses represent the measurements made the inferior angle after the degree of dilatation we्sis assessed.

Echo and pneumoencephalographic measurements were found in complete agreement for the right lateral ventricle in 19 patients and the left lateral $\frac{\partial}{0}$ ventricle in 28 (Table I).

TABLE I

\begin{tabular}{l} 
DIFFERENCE IN ECHO AND $x$-RAY MEASUREMENTS \\
$\begin{array}{l}\text { Difference of measurement } \\
(\mathrm{mm})\end{array}$ \\
\cline { 2 - 3 }
\end{tabular}

Echo $>x$-ray

1
2
3
4
5
6

Echo $<x$-ray

1
2
3
4
6


Analysing the results for both the ventricles together, correct results were obtained in eight patients, a difference up to $1 \mathrm{~mm}$ on either side in 21 patients, difference of between 1 and $2 \mathrm{~mm}$ in six patients, difference of $2 \mathrm{~mm}$ on either side in 19 patients, and difference of more than $2 \mathrm{~mm}$ on either side in 24 patients.

In one patient it was not possible to obtain echoes from the left lateral ventricle. In four patients the ventricular echoes were obtained with difficulty. In another seven patients multiple reflections were obtained on either side of the midline echo; the nearest echo to the midline was taken to be the ventricular echo.

Analysing the results, a wrong interpretation was made in 18 patients for the right ventricle and 22 patients for the left ventricle (Table II). Of the wrong results, an error was made on both sides in 10 patients.

Comparison of the results in different grades of dilatation is shown in Figures 2-6.

\section{COMMENT}

By the method described, a wrong measurement was made in $23.1 \%$ of cases for the right lateral ventricle and in $28.2 \%$ of cases for the left lateral ventricle. The majority of the false results were obtained in differentiating between the normal ventricles and minimal dilatation, and between the minimal and the slight dilatation. In no patient was a ventricular dilatation missed, the mistakes being made only in correct grading of the dilatation.

On the basis of our series, the following table of echo measurements between the midline echo and the ventricular echo is suggested:

$\begin{array}{lr}\text { Normal ventricles } & \text { up to } 7 \mathrm{~mm} \\ \text { Minimal dilatation } & 8 \text { to } 10 \mathrm{~mm} \\ \text { Slight dilatation } & 11 \text { to } 13 \mathrm{~mm} \\ \text { Moderate dilatation } & 14 \text { to } 17 \mathrm{~mm} \\ \text { Gross dilatation } & 18 \mathrm{~mm} \text { and above }\end{array}$

It is sometimes difficult to separate ventricular echoes in normal cases as they are usually joined to

TABLE II

ASSESSMENT OF ACCURACY OF DIAGNOSIS

\begin{tabular}{lcc} 
Size of ventricles & \multicolumn{2}{c}{ Patients with wrong 'echo' diagnosis (no.) } \\
\cline { 2 - 3 } as seen on $x$-ray & For right ventricle & For left ventricle \\
\hline Normal & 3 & 4 \\
Minimal dilatation & 3 & 3 \\
Slight dilatation & 6 & 6 \\
Moderate dilatation & 1 & 5 \\
Gross dilatation & 5 & 4 \\
Total & 18 & 22 \\
\cline { 2 - 3 } & $23 \cdot 1 \%$ & $28.2 \%$
\end{tabular}
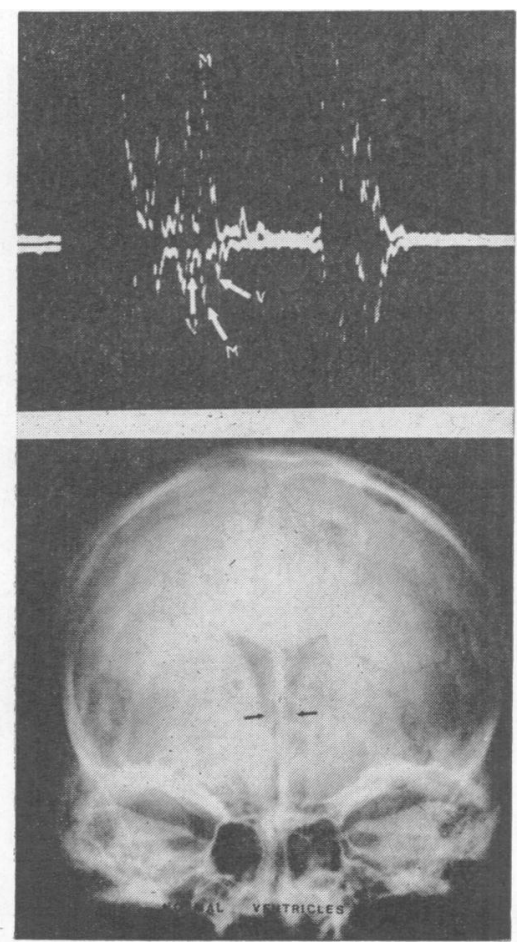

FIG. 2. (left) Normal ventricles. Arrows on radiograph indicate the level of the ventricular measurement. On the echoencephalogram, $M=$ midline echo and $\xi V=$ ventricular echo.

FIG. 3. (right) Minimal dilatation.

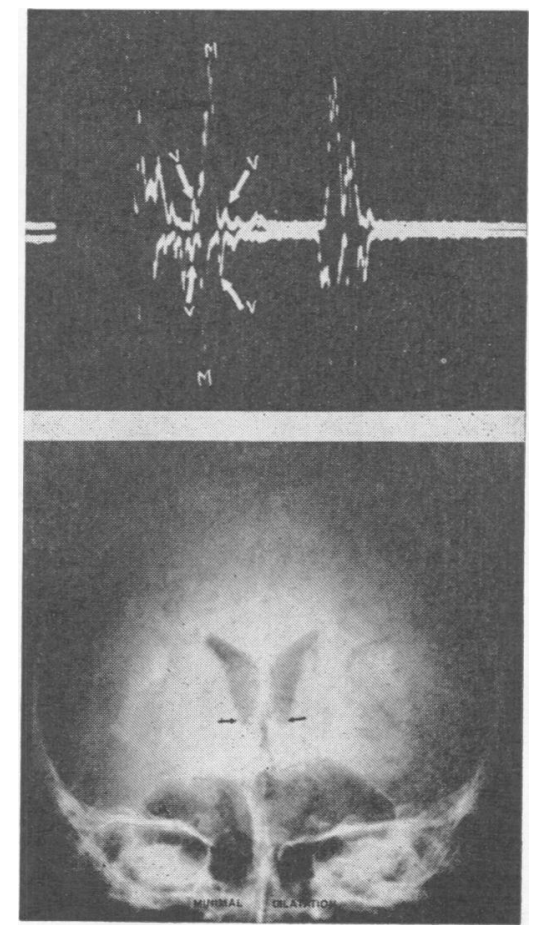



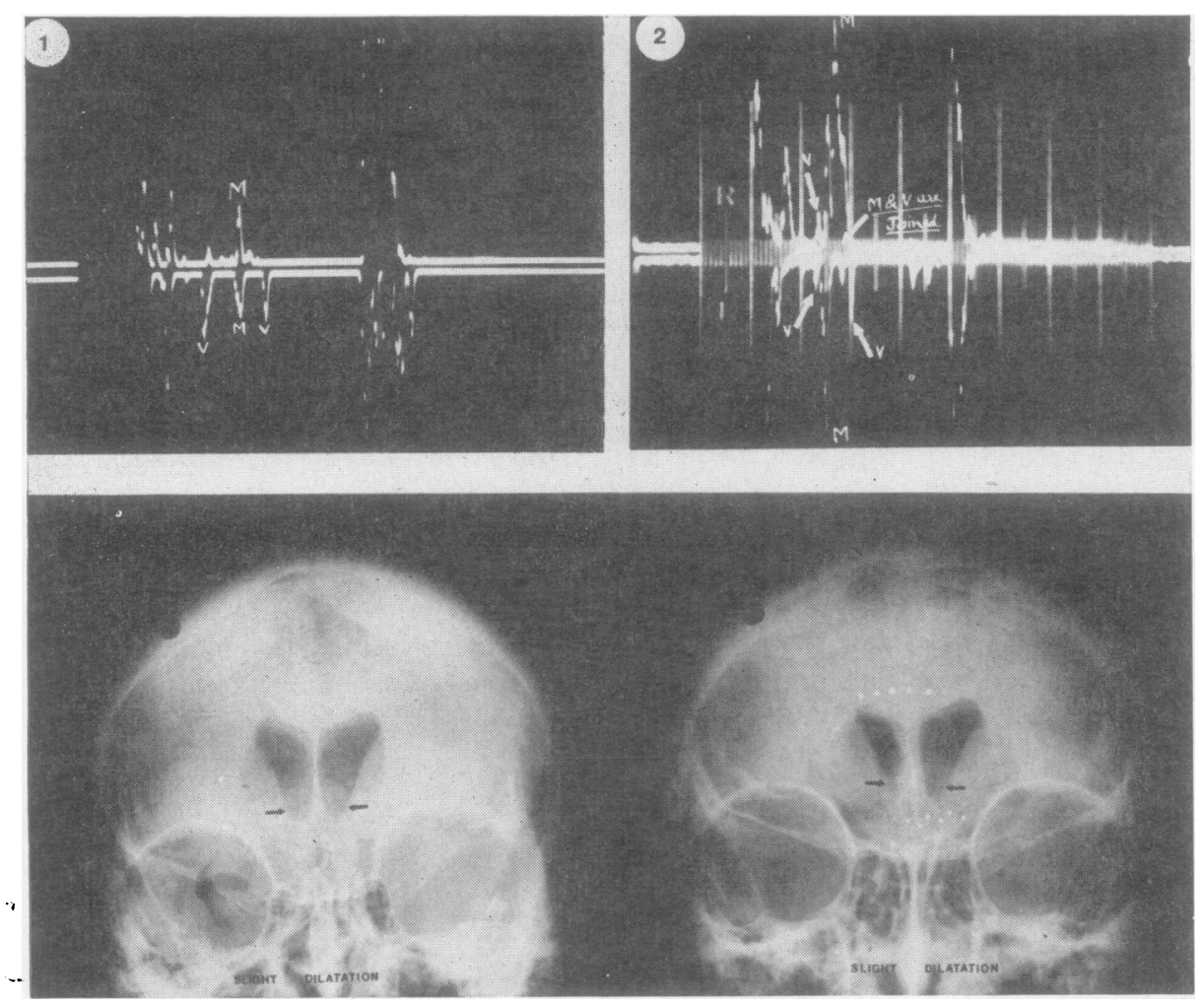

FIG. 4. Slight dilatation.
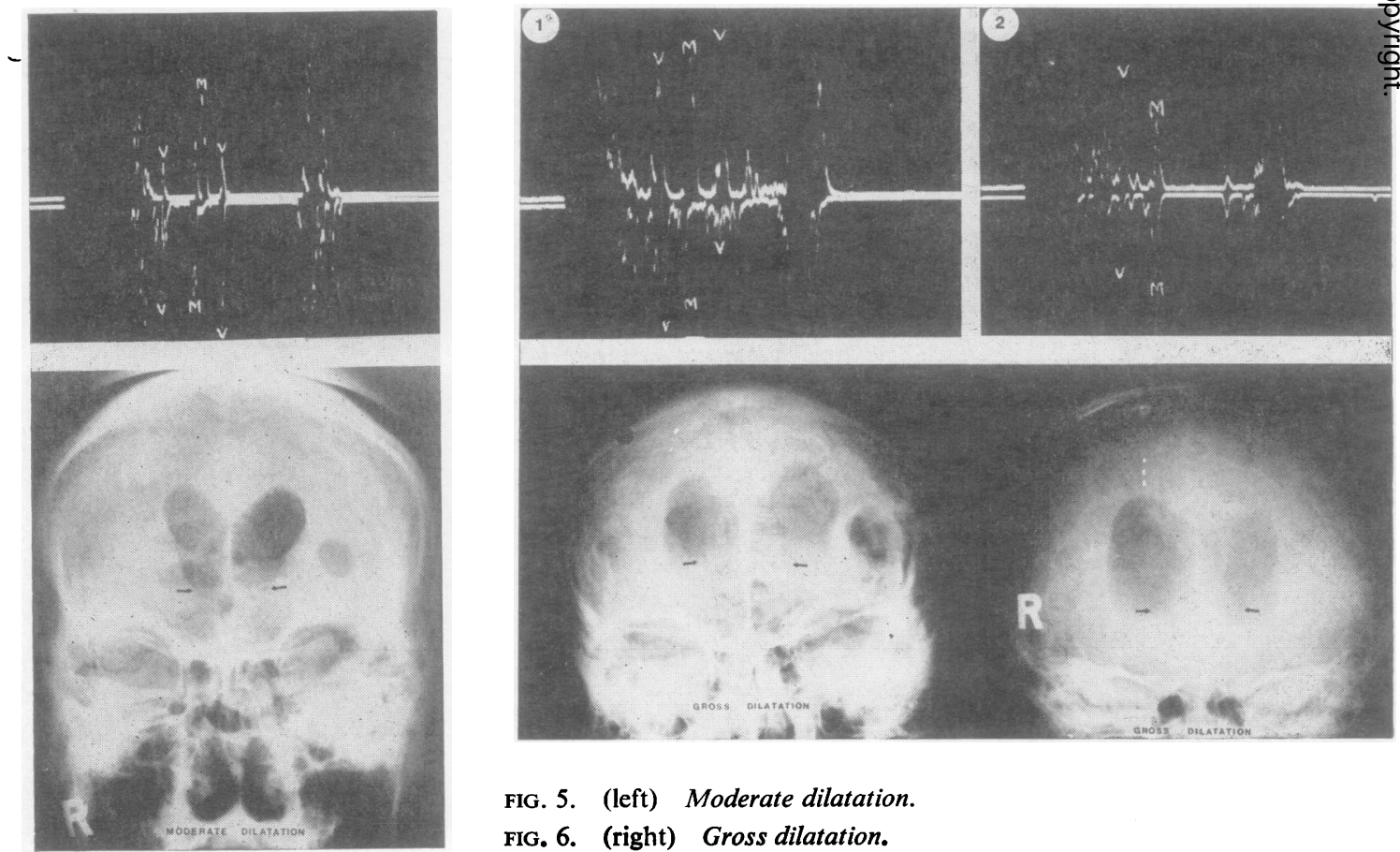

FIG. 5. (left) Moderate dilatation.

FIG. 6. (right) Gross dilatation. 
the midline echo, especially if the high impulse power is used. It is then helpful to lower impulse power until satisfactory results are obtained. It is also useful to repeat examination and compare the results for definite resolution of the echoes. The use of a smoothing control often leads to false results. It is better to use less sensitivity and pulse intensity.

Sometimes, ventricular echoes are obtained only on the near side, which prevents comparison of the right and left echoes. As indicated by Lithander (1961b) also, the echoes arising from the boundary between the thalamus and the internal capsule can occasionally be confused with ventricular echoes. When the ventricles are dilated, prominent echoes are obtained from the temporal horns on the near and far side. It is sometimes difficult to differentiate these from the lateral ventricle echoes. When multiple reflections near the midline area make differentiation difficult, the use of the transmitted impulse deflection method may be valuable.

\section{SUMMARY}

An attempt has been made to measure the size of the lateral ventricles by echoencephalography in patients with normal and dilated ventricles. The sources of error and their control are described.

It is possible to measure the lateral ventricles by echoencephalography, with an accuracy of $70-75 \%$. It is difficult to differentiate between normal and slightly dilated ventricles, the majority of mistakes being made in this group.

We wish to express our gratitude to Dr. F. S. Grebbell, of the Department of Neuro-Radiology, Royal Victoria Hospital, Belfast, for his invaluable help during this study and Professor Sir John Biggart of the Department of Pathology, Queen's University of Belfast, for his permission to perform the cadaver experiment. The work was supported by a Royal Victoria Hospital Research Grant.

\section{REFERENCFS}

Ambrose, J. (1963). Some clinical applications of ultrasound. Brit. J. Radiol., 36, 302.

- (1964). Pulsed ultrasound. Illustrations of clinical applications. Ibid., 37, 165-178.

Ballantine, H. T., Ludwig, G. D., Bolt, R. H., and Hueter, T. F. (1950). Ultrasonic localization of the cerebral ventricles. Trans. Amer. neurol. Ass., 75, 38-41.

Braak, J. W. G. ter, Crezée, P., Grandia, W.A. M., and Vlieger, M. de. (1961). The significance of some reflections in "echo-encephalography'. Acta neurochir. (Wien), 9, 382-397.

Dreese, M. J., and Netsky, M. G. (1964). Studies of lateral reflections in the echo-encephalogram. Neurology (Minneap.), 14, 521-528.

Dussik, K. T. (1948). Ultraschall Diagnostik, inbesondere bei Gehirnerkrankungen, mittels Hyperphonographie. $Z$. phys. Med., 1, 140-145.

Garg, A. G. (1966). Ultrasound in neurological diagnosis (A-Scan technique). pp. 302-322. Thesis, Queen's University, Belfast,

Gordon, D. (1959). Echo-encephalography. Ultrasonic rays in diagnostic radiology. Brit. med. J., 1, 1500-1504.

(1966). Ultrasonics in diagnosis. Bio-med. Eng., 1, 58-62.

Hueter, T. F., and Bolt, R. H. (1951). An ultrasonic method for outlining the cerebral ventricles. J. acoust. Soc. Amer., 23, 160-167.

Jacobi, G., and Stephan, U. (1965). Utber die Anwendungsmöglichkeit der Echoencephalographie bei Kindern. Mschr. Kinderheilk., 113, 344-345.

Kazner, E., Kunze, S., and Schiefer, W. (1965). Die Bedeutung der Echoencephalographie für die Erkennung epiduraler hämatome. Langenbecks Arch, klin. Chir., 310, 267-291.

Kessler, G. B. (1965). Echoencephalography. Its use as a diagnostic aid in neurological disease; plus a comparison with E.E.G. foci. Bull. Los Angeles neurol. Soc., 30, 21-26.

Kikuchi, Y., Uchida, R., Tanaka, K., and Wagai, T. (1957). Early cancer diagnosis through ultrasonics. J. acoust. Soc. Amer., 29, 824-833.

Lapayowker, M. S., and Christen, G. E. (1965). Echoencephalography in general hospital practice. Amer. J. Roentgenol., 93, 803-810.

Leksell, L. (1956). Echo-encephalography: detection of intracranial complications following head injury. Acta. chir. scand., 110, 301-315.

Lithander, B. (1961a). Clinical and experimental studies in echoencephalography. Acta psychiat. scand., 36, Suppl. No. 159. 1-53.

(1961b). Origin of echoes in the echoencephalogram. J. Neurol. Neurosurg. Psychiat., 24, 22-31.

Russo, G. L., and Arnold, J. G. (1964). Neurosurgical experience with echoencephalography. Med. Ann. D.C., 33, 260-263, and 304.

Schiefer, W., and Kazner, E. (1966). Methodik und diagnostische Möglichkeiten der Echoenzephalographie. Fortschr. Med., 4, 1-4.

Umbach, W., and Kley, M. (1965). Untersuchungen mit Ultraschall zur Diagnose und Verlaufskontrolle des kindlichen Hydrozephalus. Dtsch. med. Wschr., 90, 1313-1315.

Vlieger, M. de, and Ridder, H. J. (1959). Use of echoencephalography. Neurology (Minneap.), 9, 216-223. 